\title{
Protection of Radio-Electronic Equipment of The Robotic Ground Complex by Electromagnetic Radiation
}

\author{
. avlo Kazan ${ }^{1}$, Volodymyr Onishchenko ${ }^{1}$, Olha Korolova ${ }^{1}$, Oleh Husliakov ${ }^{2}$, Radu Budianu ${ }^{2}$, Stanislav Stetsiv $^{1}$ \\ ${ }^{1}$ Army Scientific Center, Hetman Petro Sahaidachnyi National Army Academy, Ukraine \\ pavlokua@ukr.net, onishchenkovolodymyr@gmail.com,ok_im@ukr.net, stanislav13@meta.ua \\ ${ }^{2}$ Central Scientific Research Institute of Armament and Military Equipment of Armed Forces of Ukraine, Ukraine \\ husliakov@gmail.com, budeanu_r@ukr.net
}

\begin{abstract}
This paper analyzes the problem of protection from powerful electromagnetic radiation on radio electronic means systems of the robotic ground complex. The article draws attention to the problem of protection, ensuring survivability in the face of electromagnetic terrorism and, due to the lack of universal means of protection, the importance of developing a methodology of the justification of requirements and calculation of effectiveness of existing means of protection.
\end{abstract}

The basic calculation rations for the determination of the ways and composition of the means of protection, depending on the energy parameters of the robotic ground complex the destructive effects of electromanite radiation of various origins.

The main requirements for the protection of means of protection of radio-electronic equipment of energetic objects from the destructive effects of electromanite radiation of various origins.

Keywords: radio electronic means, electromagnetic radiation, ultrashort pulse duration, plasma protection technologies, gaseous plasma media, electromagnetic gas valve, mobile robotic complex.

\section{INTRODUCTION}

This paper analyzes the problem of protection from powerful electromagnetic radiation on radio electronic means (REM) systems of the robotic ground complex. A robotic ground complex is a machine that can move in space and perform certain functions due to its specialization. The development and construction of mobile robotic systems is developing in two directions: the first is based on the creation of unique (mechanized) platforms, the second - on the use of serial chassis or products in general.

Examples of robotic systems on specialized chassis are:product "Adunok" [28] for military purposes (Belarus), multifunctional robots for security services QinetiQ (Great
Britain) [29], mobile robot for extinguishing fires (Russia) [30]. Most automakers create their own robotic concept cars that can drive on the road without a driver and even "follow" traffic rules.

As a rule, such robotic cars are created to test new technologies, and individual options are then introduced into production vehicles. So, automatic transmission, cruise control, direction of movement, engine start-stop, parking sensors, recognition of road signs, prevention of a head-on collision with an obstacle, etc., which are integral functions of the integrated control system of a mobile robot, have already entered into everyday life.However, domestic mobile robotic systems of serial or small-scale production, available for mass use in agriculture, utilities and / or law enforcement agencies, yet. In this work, developed countries announce a project for creating mobile robots based on the chassis of serial mini-tractors and outlines the concept of controlling such a robot.

These robotic ground complexes on board have a large number of semiconductor and microprocessor technology for control and communication. As an example, the electric scheme of the bumper sensors is presented in Figures 1, 2.

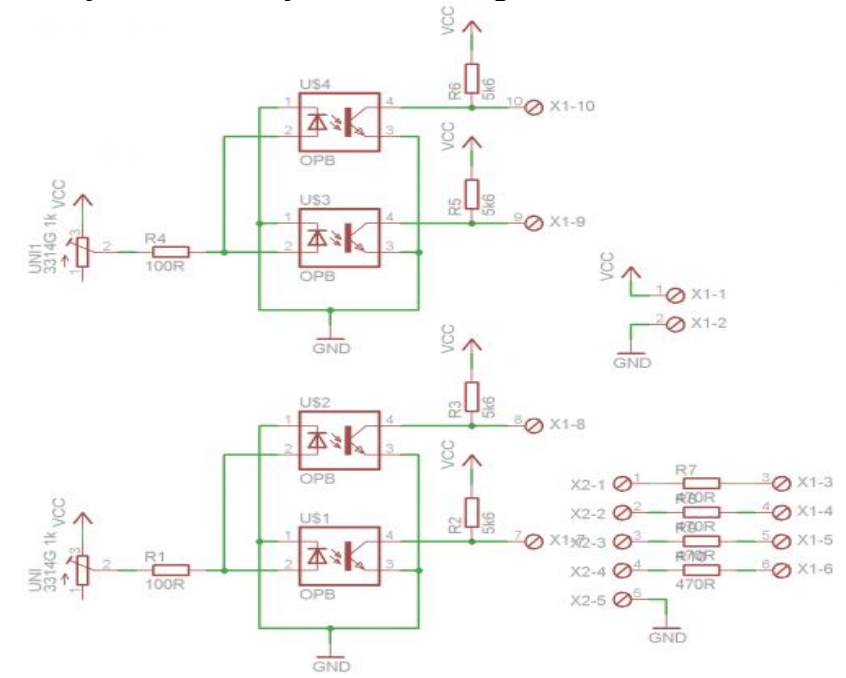

Figure 1. Electric scheme of the bumper sensors of the robotic ground complex 


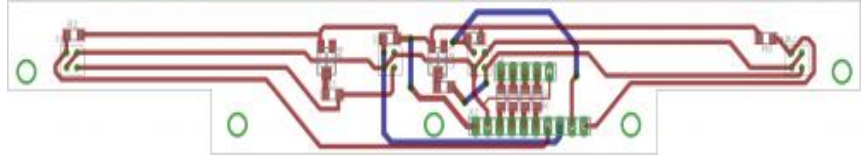

Figure 2. Assembly scheme of the bumper of the robotic ground complex

In this regard, there is a need to protect the semiconductor and microprocessor base from the destructive effects of electromanitic radiation of various origins, capable of outputting and negatively affecting the performance of the tasks of the robotic ground complex.

The purpose of the article is to develop requirements for the protection of a robotic ground complex from the destructive effects of electromanite radiation of various origins.

\section{MAIn MATERiaL}

Let's consider the approaches to defining the requirements for REM protection from EMR from a general perspective. To do this, we shall consider a generalized stochastic model for the operation of radio-electronic means (REM).

Taking into account the primary purpose of REM, we shall use the probability of completing a functional task $\left(P_{B \Phi 3}\right)$ in the condition of potential influences as a general criterion for evaluating its effectiveness. Based on this, given the state of normal functioning and reliability of the element REM base we will present $P_{B \Phi 3}$ in the following form:

$$
P_{B \Phi 3}=f\left(P_{H \Phi} ; P_{H} ; P_{E M R} ; P_{M Y} ; P_{\Pi}\right)
$$

where $P_{H \Phi}-$ is the probability of normal functioning of REM;

$P_{H}-$ is the probability of trouble-free functioning of REM

$P_{B \Phi 3}$ - electromagnetic radiation of different origins;

$P_{M Y}$ - the probability of influence of meteorological conditions;

$P_{H B \Pi}-$ the probability of unintentional interference with obstacles;

Assuming that the REM functioning is operated only by terroristic means of electromagnetic influence, $P_{B \Phi 3}$ will be determined by the spatial and energetic characteristics of the electromagnetic radiation of different origins. Based on this, we will write $P_{B \Phi 3}$ in the following form:

$$
P_{B \Phi 3}=f\left(\Pi_{B X_{E M R}}\right),
$$

where $\Pi_{B X_{E M R}}$ - is the flux of incident power generated by the electromagnetic radiation of different origins of the EMR.

The functional lesion of REM is carried out under the following condition:

$$
\Pi_{B X_{E M R}} \geq \Pi_{\Pi O P}
$$

where $\Pi_{\Pi O P}$ is the threshold value of the flux of incident power at which the functional affection of REM is carried out.

Taking into account (3) $P_{B \Phi 3}$ in the conditions of influence of the electromagnetic radiation of different origins will be determined as follows:

$$
P_{B \Phi 3}=P\left(\Pi_{B X_{E M R}} \leq \Pi_{\Pi O P}\right) .
$$

Taking into account the distance $\mathrm{R}$ between REM and the means of the electromagnetic radiation of different origins, the attenuation of the EMR energy during the distribution in the space of the electromagnetic radiation of different origins, the duration of EMR pulse $\tau_{i}$, we shall represent the flux of incident power $P_{\text {виnр }}$ at the REM input in the following way:

- for radio-frequency influence of the non-directional action:

$$
\Pi_{\Pi О P}=K_{B} \frac{P_{\text {випр }} \tau_{i} G}{4 \pi R^{2}} e^{-\alpha R},
$$

where $P_{\text {вunp }} \tau_{i}=W_{\text {вunp }}$ is the radiation energy of the pulse generator of the electromagnetic radiation of different origins, which is determined by the power and duration of the pulse radiation, respectively;

$G$ - antenna strengthening coefficient of the electromagnetic radiation of different origins;

$\alpha$ - running coefficient of attenuation of EMR on distribution path;

$R$ - distribution distance;

$K_{B}-$ coefficient of EMR usage;

- for laser influence: 


$$
\Pi_{\Pi O P}=K_{B} \frac{W_{\text {Bunp }}}{\Omega R^{2}} e^{-\alpha R}
$$

Taking into account the EMR shielding according to (2), (3), (5), we will present (4) as follows:

- for radio-frequency influence of the non-directional action:

$$
P_{B \Phi 3}=P\left(\Pi_{B X} \leq K_{B} \frac{P_{\text {вunp }} \tau_{i} G}{4 \pi R^{2}} e^{-\alpha R} 10^{-0.1 K_{E}}\right) .
$$

- for laser influence:

$$
P_{B \Phi 3}=P\left(\Pi_{B X} \leq K_{B} \frac{W_{\text {вunp }}}{\Omega R^{2}} e^{-\alpha R} 10^{-0.1 K_{E}}\right) .
$$

The expressions (7), (8) allow to determine the distance at which the functional affection of the electromagnetic radiation of different origins with the corresponding energetic parameters of a particular REM will be made, depending on the stability of its element base, which determines the threshold value of the flux of incident power at which the functional affection of the REM as well as REM shielding settings will be realized.

$$
R_{\max }=\sqrt{\frac{W_{\text {Bunp }} K_{B}}{\Pi_{\Pi O P} \Omega} e^{-\alpha R} 10^{-0.1 K_{E}}} .
$$

Let us consider that

$$
\Pi_{B X}=[E \times H]=\frac{E^{2}}{Z},
$$

where $Z=377 \Omega$.

Then taking into consideration (5) we will write:

$$
R_{\max }=\sqrt{\frac{30 P_{B И П P} G K_{B}}{E_{\Pi O P} \tau_{i}^{2}} e^{-\alpha R} 10^{-0.05 K_{E}}}
$$

Let us determine the basic requirements for protection means, based on the most common assumptions about the characteristics of the objects of protection and the electromagnetic radiation of different origins, radio-frequency and laser radiation, provided in the literature $[1,4,5,17$, $18-28]$.

Considering the duration of the EMR pulse which lies in the range of tens of nanoseconds up to $10^{-18} \mathrm{~s}$, the energy at which the degradation phenomena $10^{-4} \ldots 10^{-8} \mathrm{~J}$ occur in the most sensitive elements, and laser energy, at which the protective material will evaporate $\left(0,2 \ldots 2,5 \mathrm{~J} / \mathrm{sm}^{2}\right.$ при $\left.\tau_{\mathrm{i}}=10^{-9} \mathrm{~s}\right)$, as well as the values of the electromagnetic radiation of different origins power from 1 to $100 \mathrm{GW}$ and more [1, 2, 4, 6,29,30], the REM protection should be carried out in accordance with the principles of construction of REMs themselves, their purpose and the wide spread of EMR characteristics that can lead to REM functional affection.

A number of factors and tendencies that directly or indirectly reduce the effectiveness of the usage of devices and means of protection of REM from EMR have been recently identified. They may include the following:

- extension of the range of solved tasks by disabling REM;

- suddenness of usage;

- reducing requirements to the quality of information about the REM characteristics;

- extension of the types and further improvement of the EMR, which is aimed at increasing the energy of the electromagnetic radiation and reducing the pulse duration $\left(10^{-9} \ldots 10^{-18} \mathrm{~s}\right)$;

Due to these factors, REM devices and REM protectors from EMR must provide a shielding level in the wide bandwidth at which the EMR energy transmitted to the REM elements will not exceed the value when degradation effects occur in them $\left(\max 10^{-8} \mathrm{~J}\right)$, and the reflection of the laser energy that will not evaporate the shielding material $\left(>0,2 \ldots 2,5 \mathrm{~J} / \mathrm{sm}^{2}\right.$ при $\left.\tau_{\mathrm{i}}=10^{-9} \mathrm{~s}\right)$.

The following points should be considered when justifying the requirements:

- based on the conditions of location on the air objects, the protective means and devices must cover a small portion of the total weight and volume discharged for the payload ( $(20 \ldots 40)$ $\left.\mathrm{g} / \mathrm{m}^{2}\right)$;

- in view of the tendency to increase the flight speed of aero-ballistic objects up to $1 \mathrm{~km} / \mathrm{s}$ and more, the characteristics of the protective shielding should not depend significantly on the flight parameters, which are caused, first of all, by the temperature more of the shielding (up to 2000K) [3, 11, 12-18], that is, protection means should not severely limit the possibility of flight conditions; besides, the protection must be carried out repeatedly and without prior preparation.

- considering the possible rapid change of location of EMR means, protective means and devices should not require preparation to use them.

The creation of REM protection devices and means, in view of the basic characteristics, features of application and operation of the electromagnetic radiation of different origins, should be 
aimed at the optimal combination and implementation of the following principles:

- no influence on the process of REM functioning during the interaction with EMR;

- instantaneous response to EMR (providing the required performance based on the duration of the EMR pulse);

- energy independence or minimum allowable energy consumption;

- re-usability;

- constant or acceptable increase in the weight and overall characteristics of the objects of protection;

- practical implementation and possibility of application both on land and onboard objects.

The implementation of these principles is aimed to increase the effectiveness of REM protection from the destructive unintentional EMR and electromagnetic radiation of different origins to the maximum permissible, which will ensure the fulfillment of the functional task of REM $P_{B \Phi 3} \approx 1$.

The main requirements for REM protection from the powerful EMR UPD are [1, 13-16, 20-27]:

1. Range of operating wavelengths from $1 \mathrm{~mm}$ to $100 \mathrm{~km}$.

2. Reducing the EMR energy level at the input at the REM access points to $10^{-8} \mathrm{~J}$.

3. Activation time of at least $10^{-10} \mathrm{~s}$ for protection from radio-frequency EMR, and $10^{-19} \mathrm{~s}-$ for protection from optical radiation.

4. Ability to operate in a wide temperature range (240-2000 K).

5. Efficiency with taking into account the possibility of changes within a wide range of physical conditions of use (air pressure from 760 to $10 \mathrm{~mm}$. mer. pil).

6. Minimum mass per unit area.

7. High strength of characteristics.

\section{CONCLUSION}

A generalized stochastic model of REM of the robotic ground complex under conditions of electromagnetic terrorism has been developed.

The basic calculation ratios for the determination of the ways and composition of the means of protection, depending on the energy parameters of the means of the destructive effects of electromanite radiation of various origins.

The criterion for estimating the effectiveness of REM of the robotic ground complex functioning under conditions of electromagnetic radiation, taking into account the stochastic model of the REM functioning process, it has been proposed to use the probability of fulfilling the task in the conditions of possible influences.

The main requirements for the protection of radio-electronic equipment of the robotic ground complex from the destructive effects of electromanite radiation of various origins.

\section{REFERENCES}

1 M. Iasechko. Plasma technologies for the protection of radio electronic means from exposure to high-power electromagnetic radiations with ultrashort pulse duration, Proceedings of the 1-st Annual Conference, Tallinn, Estonia, 2017, pp. 18-21. doi: /10.21303/2585-6847.2017.00480.

2 E. M. Bazelyan and U. P. Raizer. Lightning attraction mechanism and the problem of laser lightning control, Physics-Uspekhi, 43:7, Moscow, 2000, pp. 701-716.

3 V. L. Ginzburg and A. V. Gurevich. Nonlinear phenomena in a plasma located in an alternating electromagnetic field, SOV PHYS USPEKHI, 3(1), Moscow, 1960, pp.115-146. doi:10.1070/PU1960v003n01ABEH003261.

4 O. G. Sytenko. Electromagnetic plasma fluctuations, KhGPU, Ukraine, Kharkiv, 1965, pp. 1-183.

5 V.V. Chikovani, O. A. Sushchenko, V.M. Azarskov,Yu. M. Bezkorovainyi, V. M. Korolov, O. V. Korolova. Errors Compensation of Ring-Type MEMS Gyroscopes Operating in Differential Mode. 2020 IEEE XVIth International Conference on the Perspective Technologies and Methods in MEMS Design (MEMSTECH). DOI: 10.1109/MEMSTECH49584.2020.9109476.

6 M.M. Iasechko, and O.M. Sotnikov. Advanced technologies of radio electronic equipment (means) protection from powerful electromagnetic radiations with ultra short duration of pulses exposure, Published by Izdevnieciba Baltija Publishing, Collective monograph, Riga, 2018, pp.356-385.

7 Salnyk Y., Onishchenko V., Volochiy B. Stochastic Model of the Reaction the Unattended Ground Sensor System Based on $\{3+3\}$ Scheme. Proceedings - 15th International Conference on Advanced Trends in Radioelectronics, Telecommunications and Computer Engineering, TCSET 2020, 2020, pp. 496-501.

8 O.Skoblikov and V. Knyazyev. Properties of Conductive Shells Exposed to Electromagnetic Impulse of Lightning, International Conference on Lightning Protection (ICLP'2012), Vienna, Austrian, 2012, pp. 1-8.

9 A.Tajirov, I.Cwhanovskaya, and Z. Barsova, N. Iluoykha. Chemistry and technology of magnetite and barium-containing composite materials on its 
basis, European Science and Technology: materials of the II international research and practice conference, Wiesbaden Germany, 2012, pp. 80-87.

10 V.A. Chernikov, S.A. Dvinin, A.P. Ershov, I.B.Timofeev, and V.M. Shibkov. Experimental and Theoretical research of $\mathrm{DC}$ transversal gas discharge in a supersonic gas flow, The 3rd workshop on Magneto-Plasma-Aerodynamics in Aerospace Applications, Moscow, 2001, pp. 129-134.

11 B.M.Smyrnov. Low Ionized Gas Physics, The science, Moscow, 1985.

12 S.A. Dvinin and A.A. Kuzovnikov. Plane ionization waves caused by diffusion in high frequency fields, XVII International Conference on Phenomena in Ionized Gases, Belgrade, 1989, pp. 818-819.

13 O. Sotnikov, M. Iasechko, V. Larin, O. Ochkurenko, and D.Maksiuta. The model of a medium for creation of electric hermetic screens of the radio electronic means, IJATCSE. 8(2), 2019, pp. 300-304. doi:10.30534/IJATCSE/2019/32822019.

14 M. Iasechko, O. Tymochko, Y. Shapran, I. Trofymenko, D. Maksiuta, and Y. Sytnyk. Loss definition of charged particles in the discharge gap of the opening of the box-screens during the formation of a highly conductive channel, IJATCSE. 8(1.3), 2019, pp. 1-9. doi: 10.30534/ijatcse/2019/0181.32019.

15 M. Iasechko, V. Larin, O. Ochkurenko, S. Salkutsan, L. Mikhailova, and O. Kozak. Formalized Model Descriptions Of Modified Solid-State Plasma-Like Materials To Protect Radio-Electronic Means From The Effects Of Electromagnetic Radiation, IJATCSE. $8(3), \quad 2019, \quad$ pp. 393-398. doi: 10.30534/ijatcse/2019/09832019.

16 M. Iasechko, V. Larin, O. Ochkurenko, A. Trystan, T.Voichenko, A. Trofymenko, and O. Sharabaiko. Determining the function of splitting the charged particles of the strongly ionized air environment in the openings of the case-screens of radioelectronic means, IJATCSE. 8(1.3), 2019, pp. 19-23. doi: 10.30534/ijatcse/2019/0481.32019.

17 M.M. Iasechko, and O.M. Sotnikov. Protecting of radio electronic facilities is from influence of powerful electromagnetic radiation, Published by Izdevnieciba Baltija Publishing, Collective monograph, Riga, 2019, pp.283-299.

18 A. Syrotenko, O. Sotnikov M. Iasechko, V. Larin, S.Iasechko O. Ochkurenko, and A. Volkov. Model of Combined Solid Plasma Material for the Protection of Radio-Electronic Means of Optical and Radio Radiation, IJATCSE, 8(4), 2019, pp. 1241 - 1247. doi:10.30534/ijatcse/2019/33842019.

19 V. Gurevich. Electromagnetic Terrorism: New Hazards. - Electrical Engineering and Electromechanics, N 4, 2005.

$20 \mathrm{~V}$. Manoylo. Method for determining the parameters of the electromechanical part of the electromagnetic gas metering system, power system of the transport engine, "Automobile and Electronics. Advanced technology", № 7, 2015, pp. 6-11.

21 O. Turinskyi, M. Burdin, M. Iasechko, V. Larin, Y. Gnusov, D. Ikaev, V. Borysenko, and V. Manoylo. Protection of board radio electronic equipment from the destructive powerful electromagnetic radiation with the use of natural technologies, IJETER, 7(11), 2019, pp. 542 - 548. doi: 10.30534/ijeter/2019/2371120 19.

22 M. Iasechko, V. Larin, D. Maksiuta, O. Ochkurenko, I. Krasnoshapka, Y.Samsonov, H. Lyashenko, A.Zinchenko, and R.Vozniak. Model description of the modified solid state plasma material for electromagnetic radiation protection, IJETER, 7(10), 2019, pp. 376 - $382 . \quad$ doi: 10.30534/ijeter/2019/027102019.

23 M.Iasechko, Y. Gnusov, I. Manzhai, O. Uhrovetskyi, V.Manoylo, A. Iesipov,O. Zaitsev, M. Volk, and O. Vovk. Determination of requirements for the protection of radio-electronic equipment from the terroristic influence by electromagnetic radiation, IJETER, 7(12), 2019, pp. 772 - 777. doi: 10.30534/ijeter/2019/077122019.

24 M. Iasechko, M. Kolmykov, V. Larin, S.Bazilo, H. Lyashenko, P. Kravchenko, N. Polianova and I. Sharapa. Criteria for performing breakthroughs in the holes of radio electronic means under the influence of electromagnetic radiation, ARPN Journal of Engineering and Applied Sciences, 15(12), 2020, pp. 1380 - 1384.

25 M. Iasechko, N. Sachaniuk-Kavets'ka, V.Kostrytsia, V.Nikitchenko and S. Iasechko. The results of simulation of the process of occurrence of damages to the semiconductor elements under the influence of multi-frequency signals of short duration, Journal of Critical Reviews, 7(12), 2020, pp. 109 - 112. doi:10.31838/jcr.07.13.18.

26 M. Iasechko, V. Larin, D. Maksiuta, S.Bazilo and I. Sharapa. The method of determining the probability of affection of the semiconductor elements under the influence of the multifrequency space-time signals, Journal of Critical Reviews, 7(9), 2020, pp. 569 - 571. doi: 10.31838/jcr.07.09.113.

27 O. Turinskyi1, M. Iasechko, V. Larin, T. Prokopenko, O. Kolmohorov, O. Salash, V. Tarshyn and Yu. Dziubenko. Determination of requirements for the protection of radio-electronic equipment from the terroristic influence by electromagnetic radiation, IJETER, 8(4), 2020, pp. 1333 - 1334 . doi: 10.30534/ijeter/2020/64842020.

28 http://www.adunok.by.

$29 \mathrm{http}: / /$ www.qinetiq.com.

30http://www.mchs.gov.ru/dop/info/smi/news/item/382416. 